\title{
MAMANA FANISSE, DE JOSÉ CRAVEIRINHA: ONDE A ESCRITA CARREGA DOR ${ }^{1}$
}

Avani Souza Silva

Resumo: José Craveirinha foi um poeta e escritor dos mais engajados em Moçambique contra a colonização portuguesa. Foi também um dos primeiros poetas moçambicanos a assumir os valores da Negritude e da Moçambicanidade. Sua poética é inspirada no cotidiano de seu país, que ele toma como metonímia da África: identidade africana, memórias familiares e também a fome, o abandono, a miséria, o racismo, a falta de oportunidades, a doença e a morte. A infância é um tema importante na prosa do escritor, em que ele mostra a miséria e abandono a que as crianças estavam relegadas durante o colonialismo português. Para mostrar esse aspecto da obra de Craveirinha, analisaremos o conto "Mamana Fanisse", do livro Hamina e outros contos, apontando diálogos intratextuais na obra que reforçam o tema. Com base na noção de identidade e resistência cultural concebidos por Stuart Hall (2006) focalizaremos os elementos identitários utilizados na obra pelo escritor que reforçam essas noções, como a música por exemplo.

Palavras-chave: Mamana Fanisse. Identidade cultural. Resistência cultural. Literatura moçambicana. José Craveirinha.

Abstract: José Craveirinha was one the most engaged Mozambican poets and writers opposed to Portuguese colonization. He was also one of the first Mozambican poets to assume in his work the values of Blackness and Mozambicanity. His poetics is inspired by the daily life of his country, which he takes as Africa's metonymy: African identity, family memories as well as hunger, abandonment, misery, racism, lack of opportunity, disease, and death. Childhood is an important topic in the writer's prose, by showing the misery and abandonment to which children were relegated in Portuguese colonialism. To show this aspect of Craveirinha's work, we will analyse the tale "Mamana Fanisse" of the book Hamina and other tales, pointing out intratextual dialogues that reinforce the theme in the work. Based on the notion of cultural

1 Título em língua estrangeira: "Mamana Fanisse, from Craveirinha: where the writing carries suffering". 
identity e resistance of Stuart Hall (2006) and Manuel Castells (2002), we will focus on the identity elements used by the writer, like music for instance, who reinforces this notion.

Keywords: Mamana Fanisse. Cultural identity. Cultural resistance. Mozambican literature. José Craveirinha.

Falo de milhões de homens em quem deliberadamente inculcaram o medo, o complexo de inferioridade, o tremor, a prostração, o desespero, o servilismo.

(Aimé Césaire, Discurso sobre o colonialismo) Falar uma língua é assumir um mundo, uma cultura.

(Frantz Fanon, Pele negra, máscaras brancas)

José Craveirinha é mais conhecido como poeta do que como contista. Publicou os seguintes livros de poemas que o alçaram ao lugar de um dos maiores poetas moçambicanos contemporâneos: Chibugo, Karingana wa Karingana, Cela 1, Poemas da Prisão, Obra poética, Babalaze das hienas e Maria, este último reunindo poemas inspirados em sua mulher, cuja morte prematura marcou muito sua poética. Destaca-se em sua obra poética, contudo, o livro Hamina e outros contos, onde ele realiza uma prosa com muitos dos elementos que compõem a sua obra em versos, convergindo para a denúncia social ao desnudar as agruras em que vive seu povo. Escolhemos para análise o conto "Mamana Fanisse", enfatizando o tema do abandono da infância, também já tratado pelo autor em outros contos da coletânea. Pelo fato de o autor ser principalmente um poeta, difícil desvencilhar esse aspecto de sua prosa. Assim, também discorremos 
brevemente sobre sua poesia como uma introdução à sua prosa, em grande medida também poética.

Os poemas de Craveirinha são inspirados no cotidiano de Moçambique que ele toma como metonímia da África: a fome, o abandono, a miséria, o racismo, a falta de oportunidades, a cultura moçambicana, o povo, a desumanidade do europeu colonizador, a opressão sofrida pelo trabalhador moçambicano, e outras misérias humanas típicas de um continente marcado pela opressão e dilapidação colonial, pós-colonial e imperialistas europeia e americana, como se caracterizam atualmente essas relações de opressão. O poeta enfatiza a autovalorização da cultura africana e o orgulho de ser negro como contestação aos valores coloniais que foram impostos ao país.

Craveirinha foi um dos primeiros poetas negros africanos a assumir em sua poética os valores da Negritude, exaltando a beleza da mulher negra, defendendo o negro moçambicano e denunciando a discriminação racial. Foi um dos poetas também fortemente ligado à moçambicanidade, valores culturais genuinamente regionais e posteriormente nacionais. Um tema que é recorrente em sua poética é a apresentação de elementos identitários da cultura moçambicana, tais como o tambor, a música e a dança. 
Recorrer à própria identidade, no sentido de reafirmá-la, é uma forma de resistência à cultura do outro, como nos lembra Stuart Hall (HALL, 2006).

"Mamana Fanisse" é a protagonista do conto que leva o seu nome, no qual reaparece com seu filho, a personagem Sonto, do conto "História de Sonto - o menino dos jacarés de pau", do mesmo livro Hamina e outros contos, em que ele é um menino órfão, já velho, "com cem anos de fome", que sobrevive vendendo jacarés de pau, na ponte-cais. Fanisse é uma mulher trabalhadora, que logo cedo vai para a machamba (roça, campo para lavoura, em língua ronga), pega na enxada e planta mandioca, milho, feijão. Fica o dia inteiro trabalhando, de sol a sol, com o filho enganchado nas suas costas ou nas suas ilhargas, de onde o pequeno aproveita e mama, tal como o outro Sonto. O fruto da sua plantação ela vende diariamente na calçada. E tal como Mamana Sambeca, do conto "História de Sonto, o menino dos jacarés de pau", que entoava um bordão chamando a freguesia ("Amêêê... joa! Amêêê... joa!", mariscos em língua ronga), Mamana Fanisse anuncia o preço da mandioca, milho, amendoim que vende: "Xicudo ni quinhenta" (um escudo e cinquenta centavos, em língua ronga).

O conto também aborda uma das questões cruciais do colonialismo português: o êxodo de trabalhadores para 
outros territórios. Trabalhar nas minas de ouro, platina e carvão da África do Sul era um destino muito comum durante o colonialismo português para o homem moçambicano, conhecido como "magaíza"2 ou "magaíça".

Do mesmo modo, acontecia com os trabalhadores caboverdianos que iam contratados para as roças de café e de cacau em São Tomé e Príncipe. Muitos foram com seus familiares para trabalharem em condições desumanas e com endividamentos impagáveis com as empresas portuguesas donas das plantações, e nunca mais tiveram a oportunidade de voltar a Cabo Verde, formando uma diáspora muito pobre e desassistida nas ilhas. O êxodo de trabalhadores tanto de Cabo Verde e Angola, com destino a São Tomé, quanto de moçambicanos com destino à África do Sul, destruindo famílias inteiras, foi uma das marcas muito tristes do colonialismo português.

No conto em questão, a protagonista aguarda o marido que foi trabalhar nas minas da África do Sul, em busca

2 Quando da ida ele é chamado nyiuane (do inglês new one). O termo magaíça, que significava originariamente o regressado das minas do Rand, generalizou-se e passou também a significar aquele que também ia para as minas. Se por um lado se vê no magaíza o cidadão que regressa ao país com haveres (dinheiro, mantas, catanas, machados, tecidos de ganga [tecido forte e resistente, de algodão, geralmente tingidos de azul] etc., o magaíza é em geral considerado um cidadão culturalmente deslocado e marginalizado, sendo muitas vezes enganado e roubado durante a viagem de regresso, seja na fronteira, seja nas paradas de ônibus, em diversas regiões de Moçambique (Xinavane, Xai-Xai e Inhambane). Muitas vezes nessas paragens the dão de comer carne de corvo e não de galinha que ele encomendou como refeição. Geralmente, os contratos duram 18 meses. A palavra "magaíza" ou "magaíça" provém do inglês "inglizi" com a adição do prefixo banto "ma" (LOPES et al., 2000, p. 90). 
de melhor condição financeira para a família. Em dado momento do conto, ela fica muito feliz, antevendo a possibilidade de poder comprar uma manta para o filho. Era inverno e ele sentia frio. Essa possibilidade surge com o boato repassado por Mamana Sambeca de que surgiria alguém no dia seguinte que iria anunciar o fim dos impostos pagos ao governo colonial. A felicidade de Fanisse é tanta, com a perspectiva de lhe sobrar dinheiro para a manta, que ela confidencia para Mamana Sambeca que o pai de Sonto chegaria no dia seguinte. Vê-se a miséria em que vivia Mamana Fanisse, cujos ganhos não Ihe permitiam comprar sequer uma manta para agasalhar o filho, mostrando o abandono da infância no colonialismo. E como os demais colonizados, ela ainda tinha que pagar impostos.

Elemento presente na narrativa de Craveirinha, resgatando a oralidade, é a música. O canto de músicas tradicionais africanas é mais um fator identitário que Craveirinha traz para o seu texto poético como fortalecimento da identidade e resistência cultural, como nos lembra Stuart Hall (2006). Para o sociólogo jamaicano, as identidades são definidas historicamente e não biologicamente, pois o sujeito assume identidades diferentes em diferentes contextos, e elas são não fixas e imutáveis. Lembra ainda que dentro de nós há 
identidades contraditórias, empurrando em diferentes direções, de tal maneira que nossas identificações estão sempre e a todo momento deslocadas (HALL, 2006, p. 13).

Para Stuart Hall, as identidades não são fixas e imutáveis, estão em constante processo. Esse processo, que Boaventura Sousa Santos (1999) nomeia identificação, com o qual nos projetamos em nossas identidades culturais (HALL, 2006), também se tornou provisório, variável e problemático. Essa variabilidade é que está na base da definição de Hall de que "a identidade torna-se uma celebração móvel" (HALL, 2006, p. 13). Assim, recorrer à música, cantar ou cantarolar, é uma forma de autoproteção, de identificação social e de fortalecimento da identidade cultural por parte da personagem, além de ser uma resistência cultural às demais culturas que interagem nos mundos culturais.

As principais fontes da identidade cultural no mundo moderno são as culturas nacionais. Para o sociólogo jamaicano, as culturas nacionais produzem sentidos sobre a nação, sentidos estes com os quais podemos nos identificar e que produzem identidades. Para ele, "esses sentidos estão contidos nas estórias que são contadas sobre a nação, memórias que conectam seu presente com seu passado e imagens que dela são construídas" (2006, p. 51). 
Dessa forma, as tradições orais, dentre as quais as cantigas, constituem importante contribuição para a referência cultural do homem. Fazem parte das tradições orais as músicas, as danças, a culinária, os mitos, os ritos, as lendas, contos populares, crenças, adivinhas, provérbios, métodos de cura, medicina tradicional, cantigas, rezas, benzimentos, esconjuros, superstições, anedotas, jogos, alcunhas etc. As tradições orais constroem a identidade cultural de um povo. É por intermédio delas que as comunidades humanas se conhecem e se reconhecem, transmitindo saberes e conhecimentos de geração em geração, formando com isso laços comunitários e lastros históricos.

Dito isso, retomamos à música, presente na obra em questão. As cantigas populares fazem parte da tradição oral de um povo e são vetores de identidade cultural. Ao recorrer a elas, como faz Mamana Fanisse, ela realiza um movimento de busca e de fortalecimento de sua identidade, culminando com um processo de resistência cultural, pois a identidade está em constante confronto com outros conteúdos culturais que a modificam. Então, revitalizar a música de cunho popular, da tradição, nada mais é que uma forma de resistência cultural às outras culturas que interagem nos mundos culturais. Por isso é resistência. E 
Craveirinha atua nesse sentido, como escritor e intelectual ciente de seu papel de atuar criticamente no mundo.

As culturas nacionais nas quais nascemos se constituem em uma das principais fontes de identidade cultural que foi sendo construída no interior de um sistema de representação cultural, que é a nação. As culturas nacionais são compostas não apenas de instituições culturais, mas também de símbolos e representações, como bandeiras, hinos, festas populares. "Uma cultura nacional é um discurso - um modo de construir sentidos que influencia e organiza tanto nossas ações quanto a concepção que temos de nós" (HALL, 2006, p. 50), por isso, ao produzir sentidos sobre a nação, sentidos esses com os quais nós podemos nos identificar, também constroem-se as identidades.

Segundo o sociólogo jamaicano, as identidades nacionais são construídas por intermédio "da narrativa da nação tal como ela é contada nas histórias e nas literaturas nacionais, na mídia e na cultura popular" (HALL, 2006, p. 52) Essas narrativas nos municiam de uma série de imagens, histórias, eventos, símbolos, rituais, experiências compartilhadas, desastres (e aqui citamos o holocausto; a queda do muro da Assistência, em Santiago, Cabo Verde; o ataque às Torres Gêmeas; os recentes desastres causados pela Mineradora 
Vale, em Brumadinho etc.). Todos esses eventos, compartilhados, dão sentido à nação, e nós nos vemos compartilhando dessa narrativa.

Para Stuart Hall, a ideia da nação como uma identidade cultural unificada é um mito. Ele lembra que hoje, no âmbito da Europa Ocidental que ele utiliza como exemplo, não tem qualquer nação que seja composta de apenas um único povo, uma única cultura ou etnia. Nesse sentido, nos apropriamos da síntese de Stuart Hall: "As nações modernas são, todas, hídridos culturais" (HALL, 2006, p. 62).

É de se notar que Craveirinha teve uma atuação política de resistência e luta contra o governo colonial português, engajando-se na luta de libertação nacional, o que lhe valeu perseguição pela ditadura salazarista e prisão pela PIDE Polícia Internacional e de Defesa do Estado, durante quatro anos. Nesse sentido, resgatar os elementos identitários moçambicanos para sua poética é uma atitude política de resistência do escritor à cultura colonial que era imposta pelos portugueses.

Não podemos nos esquecer de que na escola moçambicana, no período colonial, eram ensinados os valores e a língua do colonizador. Só para citarmos um exemplo, em Geografia aprendia-se os rios e os acidentes 
geográficos portugueses e não os moçambicanos, resultando, pois, em um ensino completamente desvinculado da realidade de Moçambique. O mesmo acontecia nas demais colônias africanas com outras disciplinas ou áreas de estudos como a Literatura, a Linguagem, a História, as Ciências. Com muita segurança podemos usar o adjetivo nacional, para nos referirmos ao espaço regional de Moçambique, pois embora o Estado não estivesse ainda constituído no período colonial, o que ocorreria somente após a Independência Nacional, a nação, por sua vez, já se projetava e se afirmava como uma comunidade imaginada, nos termos em que a define Benedict Anderson (1994, p. 29).

Assim, de acordo com Stuart Hall, uma nação não é apenas uma entidade política, mas uma comunidade simbólica, "algo que produz sentidos - um sistema de representação cultural. As pessoas [...] participam da ideia de nação tal como representada em sua cultura nacional" (HALL, 2006, p. 49).

Podemos destacar que o poeta, ao resgatar os elementos identitários da cultura moçambicana tornando-os sua matéria literária, de forma recorrente, ele está afirmando a cultura e a identidade moçambicanas num movimento de reafirmação identitária, de defesa de sua cultura frente às 
outras culturas. E esse elemento identitário vem associado à música, que compõe um retrato conhecido da África que é sempre e novamente pintado pelo poeta. A música está presente nas festividades, celebrações e rituais tradicionais moçambicanos. O apego aos elementos identitários nacionais como defesa de sua própria cultura é, segundo Stuart Hall, uma posição de resistência à globalização que, de certa forma, pasteuriza as culturas, fazendo emergir novas identidades. Portanto, veicular sua cultura como forma de resistência é um dos aspectos da poética de Craveirinha, consoante o projeto estético da moçambicanidade, que é justamente o de valorização da cultura e identidade moçambicanas.

Iluminando a questão da identidade, trazemos Manuel Castells, para quem a

construção de identidades vale-se da matéria-prima fornecida pela história, geografia, biologia, instituições produtivas e reprodutivas, pela memória coletiva e por fantasias pessoais, pelos aparatos de poder e revelações de cunho religioso. Porém, esses materiais são processados pelos indivíduos, grupos sociais e sociedades, que reorganizam seu significado em função de tendências sociais e projetos culturais enraizados em sua estrutura social, bem como em sua visão de tempo/espaço. (CASTELLS, 2002, p. 23)

No conto "Mamana Fanisse" há várias passagens em que Fanisse canta. E esse canto às vezes, ao lavrar a terra, tem 
um sentido de lamento, lamento de cansaço. Mas quando ela se vê próxima de comprar uma manta para o filho, e próxima da chegada do marido, seu canto é de alegria: Fanisse não resiste e canta. Seu canto é um agradecimento ao mulungo (europeu) que mata mudende (imposto, em língua ronga). Imposto este, diga-se, que eles mesmos, os europeus, criariam e com ele penalizam muito o povo, haja vista o caso de Mamana Fanisse que sonha em comprar uma manta para o filho com o dinheiro proveniente da economia com os impostos (CRAVEIRINHA, 1997, p. 75).

Todavia, no dia seguinte, no bazar (feira, em ronga), procuramna com uma carta nas mãos. Essa carta desperta maus pressentimentos em Fanisse. Ela leva a carta para uma pessoa ler. O narrador se refere a mulungu Silva, e entendemos pelo sobrenome que se trata de um português. Transcrevemos a cena da leitura da carta para compartilhar os recursos estilístico da repetição que o escritor utiliza para mostrar a disparidade do mundo insensível do colonizador e a inferioridade do colonizado:

Mulungo Silva rasgou o envelope, começou a ler.

Leu, olhou Fanisse, a Mamana que vendia no bazar as coisas da machamba, e voltou a ler. Depois Fanisse ouviu a voz fria do mulungo dizer:

- Morreu um homem chamado Matolo, lá na mina... (CRAVEIRINHA, 1997, p. 76) 
Como podemos perceber da passagem acima, Fanisse é definida como "a Mamana que vendia no bazar as coisas da machamba" (roça, lavoura, em língua ronga), que é um traço da identidade da personagem enfatizada pelo narrador e é como o português - o mulungo ${ }^{3}$ - a conhecia. Assim, a identidade da personagem está restrita à natureza de seu trabalho, nada mais a identifica para o português, nem mesmo seu nome. O escritor revela, nessa passagem, o não reconhecimento da alteridade por parte do colonizador.

A descrição da carta feita pelo narrador do ponto de vista de Fanisse é primorosa. O escritor mostra as letras como coisinhas pretas, muito alinhadas, que tem o poder de vida ou de morte, metaforizando o enorme abismo social entre o letrado e o não letrado no contexto colonial moçambicano:

Aquelas coisinhas pretas, muito alinhadas, que ela, na sua alucinação, via crescer fantasticamente para saltarem sobre o seu Matolo, talvez amarrado de pés e mãos para se não poder defender. A saltarem sobre o seu homem amarrado e a sugar-lhe o sangue até o deixarem morto. (CRAVEIRINHA, 1997, p. 76)

O desespero de Fanisse era tal, que não conseguia acreditar ainda no tamanho de sua desgraça. O narrador serve-se da ambiguidade do discurso indireto livre

3 O termo mulungo também se refere ao europeu de maneira geral. 
para mostrar ao leitor o tamanho da incredulidade da personagem, e sua adesão à matéria narrada:

"E se fosse mentira? Aquelas coisinhas pretas no papel podiam ser bichos de mentira de Mamana Xtimela, que não gostava dela." (CRAVEIRINHA, 1997, p. 77)

[...] E na ânsia de querer que tudo não fosse verdade, Fanisse quase via as coisinhas pretas de papel mexerem-se do lugar para mudarem de sentido. (CRAVEIRINHA, 1997, p. 77)

As letras são portadoras de dor, tristeza. Trazem consigo a desolação, o desespero, a viuvez, a insegurança quanto ao futuro dela e de seu filho. Nas letras miúdas e pretas moram a dor.

No final do conto, Fanisse é expulsa violentamente da terra, do barraco que ocupava na machamba, tão logo chega em casa. Ela faltara ao serviço no dia em que recebera a carta, e não valeram de nada suas súplicas, foi mandada embora. Sem trabalho, sem marido, sem perspectiva futura, e endividada porque comprara a manta para ao menino, só Ihe resta viver da prostituição. O poeta escreve de forma metafórica essas cenas, tentando amenizar do ponto de vista moral a atitude de Fanisse, resgatando para a personagem ainda o dom de cantar, como se tudo isso fosse um destino inexorável naquela África sofrida: 
Matolo morreu na mina e Mana deixou chicomo e está na vida. Cama velha é sua machamba agora. Às vezes ainda canta as cantigas fatalistas da raça, mas os vultos chegam cosidos com o escuro, as sombras juntam-se e a vida segue. (CRAVEIRINHA, 1997, p. 79)

Um aspecto interessante nesse conto é a intratextualidade com o conto "História de Sonto, o menino dos jacarés de paus". Craveirinha resgata nesse conto o menino Sonto, como filho de Mamana Fanisse. Como aquele, o menino também fica o tempo todo dependurado no peito de sua mãe enquanto ela vende os produtos, ou mesmo enquanto lavra a terra. E como aquele, também sofrerá as necessidades básicas que um menino pobre tem, aqui simbolizada pela manta. Ou seja, a criança não tem sequer uma manta para se cobrir no inverno, tamanho é o estado de penúria em que vive sua mãe. A mãe de Sonto, do conto "A história de Sonto" também ressurge em "Mamana Fanisse", com a mesma identidade "Mamana Sambeca". E tal como Mamana Fanisse, ela trabalha na roça para se sustentar. Todavia, terá o papel de trazer a boa nova: a de que o mulungo (o europeu) acabará com o imposto. E tanto ela, Sambeca, como Fanisse ficam felizes com a notícia. E Fanisse demonstra essa alegria com o canto, pois ela é uma personagem que canta para demonstrar sua paz, sua alegria. 
O uso de expressões na língua ronga, língua materna do escritor, é uma particularidade da poética de Craveirinha, com finalidade estética e política: alçar uma língua africana ao espaço literário claramente europeu e valorizar a oralidade. Importante lembrar-nos que Craveirinha era filho de pai português e de mãe africana. Todavia, embora o pai tenha continuado casado com sua mulher portuguesa, nunca abandonou os filhos da mulher negra. Por isso, Craveirinha aprendeu o ronga, a língua de casa, do afeto materno. E justamente ele vai trazer para o texto poético expressões nessa língua nacional africana como uma forma de dar-lhe um status literário, inclusive adaptando-o às regras fonológicas do português.

A presença de expressões de línguas nativas no texto literário em português nos países de colonização portuguesa é uma forma de valorização da identidade nacional, como fizeram Luandino Vieira, e mais recentemente Ondjaki, em Angola; Luís Bernardo Howana, José Craveirinha, em Moçambique, e atualmente Mia Couto, Pedro Pereira Lopes e Lucílio Manjate, só para citar alguns. Hussel Hamilton (1984) lembra que "a desintegração linguüística é tanto um desafio à língua imposta quanto uma apropriação dela". Relata que para os escritores africanos de língua 
portuguesa, e aqui citamos o caso de José Craveirinha, "desintegrar o discurso poético comedido e ir além dos limites convencionais da linguagem [...] eram em si atos revolucionários", instrumento da luta anticolonialista de que se serviu em sua poética. Luandino Vieira, em Angola, inaugura uma revolução na linguagem ao se apropriar dela como instrumento de libertação do opressor, e promover uma verdadeira africanização ou quinbundização do idioma.

A questão da colonização está muito presente na poética de José Craveirinha, seja mostrando o comportamento das personagens coloniais, seja mostrando as condições de miséria em que vivia o povo moçambicano, seja no olhar profundamente humanista que o escritor dirige ao povo, solidarizando-se com o seu sofrimento e abandono. Não há no texto de Craveirinha críticas diretas ao colonizador, senão por esse lugar que eles ocupam no espaço da narrativa, que é um lugar de alienação e de profunda rejeição ao colonizado e à sua cultura.

A política colonial portuguesa foi uma política violenta, como aliás, são todas as políticas coloniais mundiais (FANON, 1979), voltada para impor sua civilização, impor seus valores, impor sua religião, impor sua língua e sua cultura. O colonizado passa por um processo de coisificação 
e despersonalização por parte do colonizador (MEMMI, 1977). Memmi ao afirmar que o processo de colonização é um fenômeno histórico em constante metamorfose, dá atualidade às mazelas da colonização, pois buscamos nesse processo as razões de tantos desvios sociais e de tanta violência contra o homem. E é por esta razão que Mamana Fanisse, do ponto de vista do mulungo, é aquela Mamana que vendia no bazar as coisas da machamba. Ela não tem uma identidade própria, uma individualidade, pois o processo colonial coisifica o colonizado e o pluraliza como uma entidade, não como um indivíduo.

Portugal teve nas suas colônias uma missão civilizadora, renegando as culturas, as línguas nacionais, as religiões africanas, que foram terminantemente proibidas pelo estado colonial. Assim, a colonização foi um processo deletério para a cultura moçambicana, e o escritor José Craveirinha tentou resgatar a identidade de seu povo para dentro de sua poética ao trazer para o cenário as línguas nacionais, os costumes, e todos os elementos identitários que fazem parte de sua matéria literária: o tambor, a música, a dança, as cantigas tradicionais. E mais: trazendo para o seu mundo literário as profundas diferenças de classe de seu país, como retratado no conto "Natal", de Hamina, em que uma criança 
fica totalmente à margem das comemorações de Natal. Faminta, tenta vender aspargos de porta em porta, enquanto os europeus, seus potenciais compradores, não lhe dão a mínima atenção, ocupados que estão com os preparativos para a festa de Natal, acorrendo às lojas para comprar os presentes. Aqui também a infância é relegada ao abandono e ao desprezo por parte dos colonizadores.

Os contos reunidos em Hamina são textos que foram publicados em jornais, sobretudo n'O Brado Africano, privilegiando a linguagem poética e o sentimento do humano, fazendo cumprir a principal função da literatura, de acordo com Antonio Candido (1976), que é a de humanizar o homem. No conto "Mamana Fanisse", as lentes estão focadas na mulher, protagonista de resistência e de luta contra a situação de abandono a que está relegada a população moçambicana. Se de um lado é mostrada a fragilidade da mulher e da criança frente à opressão colonial, de outro é mostrada a resistência e força dessas personagens, que acabam sucumbindo ao poder colonial massacrador e desumanizador, delineando o aspecto de denúncia social na obra poética de Craveirinha.

Mamana Fanisse, ao vender os produtos de sua "machamba" (amendoim, milho e mandioca), anunciando: 
"Xicudo ni quinhenta!". Sua voz canta nos bazares. Ao mostrar essa cantiga de trabalho, Craveirinha recorre a elementos identitários africanos, reforçando a identidade cultural. As cantigas de trabalho são antigas e no mundo africano são identitárias, falam de sua cultura, da disposição de seu povo, de seus costumes.

O conto em questão estabelece um diálogo fecundo com a poética do escritor, manifestando-se na intratextualidade do poema "Elegia à minha avó Fanisse", em que o escritor homenageia sua avó materna, que era ronga. Nesse poema, por intermédio de anáforas da expressão "ninguém" e de imagens representativas da situação de vulnerabilidade social imposta aos negros pelo processo colonial, o autor desvela a violenta situação social que permeava o momento histórico em que sua avó viveu, mas que não a afetou fisicamente, porém socialmente. Apontamos os laços dialógicos da obra, trazemos ao texto a "Elegia à minha avó Fanisse":

Fanisse era minha avó E sombra de canhoeiro no caminho de areia Traz recordação de velha capulana de riscado Com amendoim e milho maduro Na machamba de Michafutene A dois gritos de paragem de camião.

Fanisse nasceu nos meus olhos mulatos

E viveu chicomo na velhice

Batata-doce castanha de caju 
Esteira debaixo da mangueira

História de coelho esperto à volta da fogueira

Reza essencial em língua de Mahazul

E lua grande no sítio do coração.

Ninguém zangou avó Fanisse

Ninguém cuspiu sina de Fanisse

Ninguém roubou mandioca

Ninguém bateu

Ninguém matou Fanisse?

Português abriu estrada na machamba

Buzina de Thornicroft lá longe

Espantou cabrito de cocuana Mabota

Fugiu!

Ninguém cuspiu

Ninguém bateu avó Fanisse

Ninguém matou...

Ninguém fez mal.

Mas foi assim em Michafutene

Que minha avó Fanisse morreu! 4 (CRAVEIRINHA, 1999, p. 42-43)

Ao trazer o nome de sua avó para o título do conto, o autor não só homenageia a avó, mas, por extensão, todo o povo ronga, denunciando parte de seus suplícios durante o governo colonial. No caso específico da avó: não foi

4 Segue a tradução das palavras em ronga do poema, traduzidas pelo jornalista moçambicano Eduardo Quive, editor da Revista Literatas (on line), a quem agradecemos. Canhoeiro: árvore típica do sul de Maputo e tradicional na Província de Maputo, dá um fruto afrodisíaco chamado canhu, com o qual se faz bebidas; Thornicroft: veículo antigo, de fabricação inglesa, utilizado por brancos no governo colonial. Também se refere a um navio ou fragata de guerra construído pela empresa naval inglesa chamada Vosper Thornycroft. Por extensão, o nome se refere à própria embarcação. Chicomo: enxada; cocuana: velha, refere-se carinhosamente à avó; Mabota é um apelido, e no caso se refere à avó do autor: velha Mabota, avó Mabota. Há também uma localidade em Inhambane, no sul de Moçambique, com o nome Mabota. Língua de Mahazul: língua ronga; Mahazul é um herói guerreiro do povo ronga; Michafutene - Distrito de Marracuene, província de Maputo. Michafutene tem caminhos e estradas de muita areia, devido à composição do próprio solo da região. Imagens da localidade podem ser obtidas na internet. 
xingada, não foi cuspida, não apanhou, não foi morta, não teve sua mandioca roubada, ninguém fez mal a ela, embora o português tenha acabado com sua roça, abrindo sobre ela uma estrada. Esse aspecto do poema mostra que os malefícios da colonização são irrecorríveis. As personagens Mamana Fanisse e seu filho representam metaforicamente Moçambique e metonimicamente toda a África, uma vez que, sabemos, o sofrimento imposto pelo colonialismo europeu é compartilhado por outros povos do continente no período sócio-histórico de que fazia parte cocuana Mabota, a avó Fanisse.

O filho de Mamana Fanisse, Sonto, que é também o nome do filho de Mamana Sambeca em outro conto já referido aqui, representa simbolicamente a criança no colonialismo português em Moçambique, sendo que esta personagem se apresenta com três dimensões: o nome, o fato de mamar e o frio que sente. Essas dimensões sintetizam toda a personagem e seu abandono, porque ele é apenas mencionado como uma carência, uma falta. Sua humanidade é representada com um nome, com o qual nem sequer é chamado na narrativa; com um fato que é o de mamar; e com uma situação que é de frio. Esses três aspectos são o que conferem uma humanidade silenciosa 
à personagem, situação que nos remete às noções de coisificação do colonizado postuladas por Albert Memmi (1977). E uma criança passar frio (e fome) demonstra carências fundamentais para o seu desenvolvimento físico e emocional, apontando a crueldade que o colonialismo representou para a infância.

É de se notar que as carências e o sofrimento que o colonialismo português em Moçambique impôs às crianças também são retratados em poemas de Craveirinha como, por exemplo, "Um céu sem anjos de África", "Elegia a uma mulher de seis anos" e "Natal" (CRAVEIRINHA, 1999, passim). Esse último poema estabelece um diálogo intratextual com o conto de mesmo nome da coletânea Hamina e outros contos.

Por fim, lembramos que Sonto em ronga significa domingo e era o apelido familiar de infância do escritor, dado por sua avó Fanisse. $O$ fato de o autor usar seu apelido para nomear duas personagens crianças, vulneráveis a toda sorte de abandono pelo colonialismo, fortalece as laçadas dialógicas da obra em questão. Na análise do conto, traçamos um panorama do colonialismo português em Moçambique, enfocando a opressão da mulher e da criança, e de como é possível a resistência humana e cultural a partir do apego a símbolos identitários como a música. 


\section{Referências}

ANDERSON, Benedict. Comunidades Imaginadas - Reflexões sobre a origem e a difusão do nacionalismo. São Paulo: Companhia Das Letras, 1994. CANDIDO, Antonio. Literatura e sociedade. São Paulo: Cia. Editora Nacional, 1976.

CASTELLS, Manuel. O poder da identidade - a era da informação: economia, sociedade e cultura. 3. ed., Vol. 2. Tradução de Klauss Brandini Gerhardt. Rio de Janeiro: Paz e Terra, 2002.

CRAVEIRINHA, José. Cela 1. Lisboa. Lisboa/ Maputo: Edições 70, Instituto Nacional do Livro e do Disco, 1980.

CRAVEIRINHA, José. Karingana ua Karingana. Lisboa/Maputo: Edições 70, Instituto Nacional do Livro e do Disco, 1982

CRAVEIRINHA, José. Babalaze das hienas. Maputo: Associação dos Escritores Moçambicanos, 1997.

CRAVEIRINHA, José. Hamina e outros contos. Lisboa: Caminho, 1997.

CRAVEIRINHA, José. Maria. Maputo: Ndjira, 1998.

CRAVEIRINHA, José. Obra poética. Lisboa: Caminho, 1999.

CRAVEIRINHA, José. Poemas da prisão. Lisboa: Texto, 2004.

FANON, Franz. Os condenados da Terra. Rio de Janeiro: Paz e Terra, 1979.

HALL, Stuart. A identidade cultural na pós-modernidade. Tradução de Tomaz Tadeu da Silva e Guacira Lopes Louro. Rio de Janeiro: DP\&A, 2006. HAMILTON, Hussel. Literatura africana, literatura necessária. Lisboa: Edições 70, 1984.

LOPES, Armando Jorge et al. Moçambicanismos: para um léxico de uso do português moçambicano. Maputo, Moçambique: Editora Universitária, Universidade Eduardo Mondlane, 2000.

MEMMI, Albert. O retrato do colonizado precedido pelo retrato do colonizador. Tradução de Roland Corbisier e Mariza Pinto Coelho. Rio de Janeiro: Paz e Terra, p. 77-84, 1977. 


\section{Avani Souza Silva}

Doutora pelo Programa de Pós-graduação em Estudos Comparados de Literaturas de Língua Portuguesa da Universidade de São Paulo.

Licenciada na mesma Universidade em Língua Portuguesa e Literaturas Brasileira e Portuguesa e Especialista em Língua Portuguesa pela Pontifícia Universidade Católica de São Paulo.

Pesquisadora de literatura e cultura dos países africanos de língua portuguesa e de narrativas orais de Goa, Macau e Timor-Leste.

É autora do livro infantil A África recontada para crianças, da Editora Martin Claret (2020).

Email: avanissilva@yahoo.com.br 